\title{
EDITORIAL
}

\section{The hidden costs of environmental contamination}

\author{
Philip J. Landrigan
}

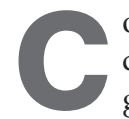
ost is an inevitable, but often overlooked and uncounted, consequence of environmental contamination. Any degradation of the environment, whether it is contamination of air or water, pollution of landfills by toxic waste or exposure of children to hazardous chemicals, carries costs. Among these costs are: 1) direct medical expenses for persons made ill by toxic exposures; 2 ) indirect health-related costs such as time lost from school or work, costs of rehabilitation and costs of special education; 3) diminished economic productivity in persons whose brains, lungs or other organ systems are permanently damaged by toxic exposures; 4) loss of irreplaceable environmental treasures such as the Everglades or the Black Forest; and 5) the costs of environmental clean-up.

A methodology for estimating the costs of diseases caused by environmental contamination was developed in the US in the early 1980s by an expert committee convened by the Institute of Medicine and chaired by Stanford University's Nobel Laureate in Economics, Prof. K. Arrow [1]. The core of this methodology is the calculation of the "fractional contribution" of the environment to causation of a particular disease in a particular population. This environmentally attributable fraction (EAF) is defined as: "the percentage of a particular disease category that would be eliminated if environmental risk factors were reduced to their lowest feasible levels" [2].

The EAF for a particular disease, such as childhood asthma, may be converted to an estimate of the cost of that disease in a particular population using the following equation:

$$
\begin{gathered}
\text { Costs }=\text { disease rate }(\text { incidence or prevalence }) \times \mathrm{EAF} \times \\
\text { population size } \times \text { cost per case }
\end{gathered}
$$

Costs are traditionally divided into direct and indirect healthrelated costs, and both are included in the calculation.

The EAF model has now been used in a series of important cases to assess the costs of environmental and occupational disease. Findings from these analyses have had powerful impacts on the health and well-being of societies around the world.

In one of its earliest applications, the EAF approach was used in 1989 in New York State, USA, to estimate the fractional costs of four categories of illness attributable to occupational exposures: cancer, chronic respiratory disease, cerebrovascular and cardiovascular disease, and end-stage renal failure. This analysis found that, using fairly conservative assumptions, occupational exposures resulting in these four diseases cost more than $\$ 600$

CORRESPONDENCE: P.J. Landrigan, Dept of Preventive Medicine, Children's Environmental Health Center, Mount Sinai School of Medicine, 17 East 102nd Street, Room D3-145, New York, NY 10029-6574, USA. E-mail: phil.landrigan@mssm.edu million per year, with the largest proportion (80\%) due to occupationally related cancer [3]. This analysis persuaded the New York State Legislature to allocate funds to support a statewide network of clinical centres of excellence in occupational medicine that continue to the present day to provide medical care to employees injured or made ill at work.

A similar approach was used by LEIGH et al. [4] to calculate the costs of occupational disease and injuries across the USA. That estimate found that the total direct ( $\$ 65$ billion) plus indirect ( $\$ 106$ billion) medical costs were \$171 billion per year for 1992. Of the total, occupational injuries cost $\$ 145$ billion and illnesses $\$ 26$ billion [4]. LEIGH et al. [5] recently updated these analyses and found that for 2007 the total estimated annual costs for occupational injuries and diseases combined had risen to approximately $\$ 250$ billion.

Economic costs of disease in children caused by harmful exposures in the environment have been examined. A 2002 report by LANDRIGAN et al. [6] analysed the costs of four categories of paediatric illness for which there is published evidence for an environmental contribution: lead poisoning, asthma, cancer and neurobehavioral disorders. EAFs were judged by expert panels to be $100 \%$ for lead poisoning, 30\% (range 10-35\%) for asthma, 5\% (range $2-10 \%$ ) for cancer and 10\% (range 5-20\%) for neurobehavioral disorders. The total annual costs of the fractions of these four diseases due to environmental exposures were estimated in 1997 US dollars to be $\$ 54.9$ billion (range \$48.8-64.8 billion): \$43.4 billion for lead poisoning, \$2.0 billion for asthma, $\$ 0.3$ billion for childhood cancer, and $\$ 9.2$ billion for neurobehavioral disorders. The single largest component of these costs was the diminished lifelong economic productivity that resulted from permanent reduction in cognitive capability (IQ score) in children exposed to neurotoxic chemicals, such as lead, in early life.

These data provided a powerful argument in support of the US government's decision to allocate funds to the National Children's Study, a prospective epidemiological study that plans to follow 100,000 children across the US from early pregnancy to age $21 \mathrm{yrs}$ with the aim of discovering potentially preventable environmental causes of disease [7].

The above cost estimates of disease in children were updated and expanded in 2011 by TRASANDE and LIU [8]. By incorporating new information on environmental causation of disease and by updating estimates on cost of illness, they found that the annual costs of lead poisoning, prenatal methylmercury exposure, childhood cancer, asthma, intellectual disability, autism and attention deficit hyperactivity disorder in US children currently amount to $\$ 76.6$ billion [8]. 
Economic analysis can also be used to quantify the benefits of economic improvements. GROSSE et al. [9] undertook a combined epidemiologic and economic analysis to quantify the economic benefits of removing lead from the US gasoline supply. They found that from 1976 to 1999, the total decline in mean blood lead level in US children aged 1-5 yrs that resulted from the removal of lead from gasoline was $15.1 \mu \mathrm{g} \cdot \mathrm{dL}^{-1}$. They calculated that this decline in lead levels produced a gain in the mean IQ score of US children of between 2.2 and 4.7 points. Because each IQ point increases a child's economic productivity over a lifetime by $1.76-2.38 \%$, the authors estimated that removing lead from gasoline has generated an economic benefit in each year's birth cohort since the 1990s of $\$ 213$ billion (range $\$ 110$ to $\$ 318$ billion); an aggregate economic benefit over the past two decades of more than $\$ 3$ trillion [9].

This striking finding has influenced countries around the world to remove lead from gasoline. Sharp declines in population blood lead levels have been documented in country after country. Today, only a handful of nations still use tetraethyl lead as a fuel additive [10].

Those reports form the backdrop to the elegant study by BRANDT et al. [11] on the economic costs of childhood asthma in the USA in this issue of the European Respiratory Journal. To estimate the social burden and economic costs of asthma due to traffic-related air pollution in the two Southern California communities of Long Beach and Riverside, BRANDT et al. [11] used an EAF approach. They skilfully distinguished the fraction of asthma due to local traffic-related pollution from that due to regional air pollution in Southern California. They examined the direct medical and the indirect health-related costs of five adverse outcomes associated with asthmatic episodes: school absences, antibiotic prescriptions, medical office visits, emergency room visits and hospitalisations. They incorporated new epidemiologic data showing that traffic-related pollution not only exacerbates pre-existing asthma, but that it is also capable of causing new asthma in previously unaffected children [12-15]. This information has not been previously incorporated into risk assessments or cost calculations for childhood asthma. The key findings are that asthma attributable to traffic-related air pollution costs at least $\$ 18$ million each year in the communities of Long Beach and Riverside, and that new cases of asthma due to traffic-related pollution account for almost half of this total cost. The methodological approaches developed in this study promise to have global implications for urban planning and the siting of major roadways.

A common theme that runs through all of these analyses of the costs of occupational and environmental diseases is their focus on identifying and quantifying costs that had previously been overlooked or hidden. These analyses may, therefore, be viewed as examples of a powerful new approach to measuring the impacts of environmental contamination termed full cost accounting or green accounting [16]. Full cost accounting is an approach to accounting practice that attempts to explicitly consider and quantify the environmental, health and social costs of business or governmental operations. Full cost accounting differs from traditional accounting, which meticulously tabulates the costs of materials, labour and energy, but fails to consider, or "externalises", the costs of factors that fall outside conventional market mechanisms, such as environmental degradation and illness. The goal of full cost accounting is to develop monetary values for these externalities, many of which have the potential to profoundly affect the health and well-being of society. Full cost accounting is growing in its application $[17,18]$. It has the potential to fundamentally transform business practice and governmental operations.

At this point, it is worth posing the question: why should physicians and epidemiologists care about monetising the costs of environmental degradation or calculating the costs of diseases caused by toxic chemicals? Economic analyses and full cost accounting certainly fall far outside the scope of traditional medical education and epidemiologic practice.

Perhaps the most important argument in support of the notion that doctors should know something about economics is that economic information can be a very powerful tool for disease prevention [19]. Accurate information on the previously hidden costs of diseases of environmental origin can be a persuasive adjunct to clinical, pathophysiologic and epidemiologic data. Economic data can sway the opinions of elected officials and governmental policy makers. It is relatively easy for an industry to calculate the one-time costs of installing pollution controls and much more difficult for epidemiologists and economists to develop accurate information on the costs of pollution because these hidden costs are typically spread across populations and extend over many years $[19,20]$. However, economic data on the costs of disease can help counter one-sided arguments put forward by business interests that focus exclusively on the costs of preventing pollution [21]. They can be very important in the setting of priorities and in the allocation of scarce resources.

In summary, information on the costs of disease caused by environmental contamination can lead to major policy changes, save hundreds of billions of dollars and improve the lives of generations. That is why this information is worth developing and why the study by BRANDT et al. [11] is so important.

\section{STATEMENT OF INTEREST}

None declared.

\section{REFERENCES}

1 Institute of Medicine. Costs of Environment-Related Health Effects: A Plan for Continuing Study. Washington, National Academy Press, 1981.

2 Smith KR, Corvalin CF, Kjellstrom T. How much global ill health is attributable to environmental factors? Epidemiology 1999; 10: 573-584.

3 Fahs MC, Markowitz SB, Fischer E, et al. Health costs of occupational disease in New York State. Am J Ind Med 1989; 16: 437-449.

4 Leigh JP, Markowitz S, Fahs M, et al. Costs of occupational injuries and illnesses. Arch Intern Med 1997; 157: 1557-1568.

5 Leigh JP. Economic burden of occupational injury and illness in the United States. Milbank Q 2011; 89: 728-772.

6 Landrigan PJ, Schechter CB, Lipton JM, et al. Environmental pollutants and disease in American children: estimates of morbidity, mortality, and costs for lead poisoning, asthma, cancer, and developmental disabilities. Environ Health Perspect 2002; 110: 721-728. 
7 Landrigan PJ, Trasande L, Thorpe LE, et al. The National Children's Study: a 21-year prospective study of 100,000 American children. Pediatrics 2006; 118: 2173-2186.

8 Trasande L, Liu Y. Reducing the staggering costs of environmental disease in children, estimated at $\$ 76.6$ billion in 2008. Health Aff (Millwood) 2011; 30: 863-870.

9 Grosse SD, Matte TD, Schwartz J, et al. Economic gains resulting from the reduction in children's exposure to lead in the United States. Environ Health Perspect 2002; 110: 563-569.

10 United Nations Environment Programme. Lead in gasoline international patterns of use. www.chem.unep.ch/pops/pdf/lead/ leadgas.pdf

11 Brandt SJ, Perez L, Künzli N, et al. Costs of childhood asthma due to traffic-related pollution in two California communities. Eur Respir J 2012; 40: 363-370.

12 Clark N, Demers P, Karr C, et al. Effect of early life exposure to air pollution on development of childhood asthma. Environ Health Perspect 2010; 118: 284-290.

13 Ryan PH, Holguin F. Traffic pollution as a risk factor for developing asthma: are the issues resolved? Am J Respir Crit Care Med 2010; 181: 530-531.
14 Anderson HR, Favarato G, Atkinson RW. 2011. Long-term exposure to air pollution and the incidence of asthma: meta-analysis of cohort studies. Air Qual Atmos Health 2011; 4: 1-10.

15 Gehring U, Wijga AH, Brauer M, et al. Traffic-related air pollution and the development of asthma and allergies during the first 8 years of life. Am J Respir Crit Care Med 2010; 181: 596-603.

16 Full cost accounting. http://en.wikipedia.org/wiki/Full_cost_accounting Date last accessed: May 28, 2012. Date last updated: April 15, 2012.

17 Epstein PR, Buonocore JJ, Eckerle K, et al. Full cost accounting for the life cycle of coal. Ann N Y Acad Sci 2011; 1219: 73-98.

18 National Research Council. The Hidden Costs of Energy: Unpriced Consequences of Energy Production and Use. Washington, National Academy Press, 2009.

19 Goodstein ES, ed. Economics and the Environment. 6th Edn. New York, John Wiley and Sons, 2011.

20 Arrow KJ, Cropper ML, Eads GC, et al. Is there a role for benefitcost analysis in environmental, health, and safety regulation? Science 1996; 272: 221-222.

21 Krugman P. Springtime for Toxics. New York Times. December 25, 2011. www.nytimes.com/2011/12/26/opinion/krugman-springtimefor-toxics.html 